the municipal service by local governments.

Keywords: municipal service, constitutional tasks for local self-government bodies and their apparatus, ensuring authorities

БОНДАРЕНКО Оксана Ивановна - кандидат социологических наук, доцент; преподаватель колледжа экономики и финансов Саратовского социально-экономического института - филиала Российского экономического университета им. Г.В. Плеханова (410052, Россия, г. Саратов, ул. Международнал, 24; oksana1136@yandex.ru)

ОЛЬХОВА Лариса Анатольевна - кандидат экономических наук, доцент кафедры управления персоналом и психологии Саратовского социально-экономического института - филиала Российского экономического университета им. Г.В. Плеханова (410003, Россия, г. Саратов, ул. Радищева 89; 766627@mail.ru)

ПАДАЛКА Екатерина Алексеевна - старший преподаватель кафедры управления персоналом и психологии Саратовского социально-экономического института - филиала Российского экономического университета им. Г.В. Плеханова (410003, Россия, г. Саратов, ул. Радищева 89; ekaterina. padalka@inbox.ru)

\title{
ПРОБЛЕМЫ ПРИМЕНЕНИЯ МЕТОДИК НОРМИРОВАНИЯ ГОСУДАРСТВЕННЫХ УСЛУГ
}

Аннотация. Интерес к нормированию труда со стороны государственных учреждений связан с решением ряда задач. Первая - повышение эффективности предоставления государственных услуг населению; вторая - разработка нормативов времени на выполнение государственных услуг; третья - определение численности персонала государственного учреждения. Результатом решения данных задач стали разработанные технико-нормировочные карты работников лаборатории государственного учреждения.

Ключевые слова: нормирование труда, методики нормирования труда, государственные услуги, типовые нормы времени, технико-нормировочные карты

$\mathrm{B}$ настоящее время существенный интерес проявляется к инструментам повышения эффективности оказания государственных услуг профильными организациями. С этой целью анализируется содержание, актуальность и трудоемкость выполняемых работ. Одним из инструментов определения затрат времени на оказание государственных услуг выступает нормирование труда.

С нашей точки зрения, нормирование труда - это процедура установления затрат времени на выполнение трудовых операций, выполняемых в конкретных организационно-технологических условиях.

С этой целью применяются различные методы нормирования. Под методами нормирования будем понимать инструменты анализа трудового процесса, вычленения трудовых операций и затрачиваемого на их выполнение времени, а также выявления и учета факторов, влияющих на разработку нормативов и норм труда.

Применительно к изучению затрат времени на оказание государственных услуг чаще применяется термин «методика нормирования». Проанализировав труды отечественных исследователей вопросов нормирования труда Б.М. Генкина, В.Б. Бычина, С.В. Малинина, А.И. Рофе, мы не обнаружили четкой трактовки данного понятия. В этой связи под методикой нормирования будем понимать совокупность методов, приемов, процедур определения затрат рабочего времени на выполнение трудовой операции в конкретных организационно-техно- 
логических условиях, а также выявления и корректировки норм труда и нормативов выполнения работ.

В настоящее время категория нормирования труда детально проработана для производственной сферы. Как правило, при характеристике норм труда используются термины «рабочая смена», «единица работ», «норма обслуживания, понимаемая как число объектов, которые работник соответствующей квалификации обязан обслужить в течение единицы времени» и т.д. Но не всегда их можно применить для описания государственной услуги, т.к. в ее реализации могут принимать участие несколько государственных учреждений, причем не последовательно, а параллельно.

В этой связи рассмотрим основные проблемы применения методик нормирования государственных услуг.

Изучение трудоемкости функций, выполняемых в рамках оказания государственной услуги, может производиться по двум направлениям. Во-первых, это затраты времени на осуществление трудовых операций конкретным сотрудником организации, оказывающей государственные услуги. Во-вторых, это затраты труда всех лиц, участвующих в оказании конкретной государственной услуги.

На настоящий момент применяется несколько инструментов для определения затрат труда в рамках данных направлений.

Для изучения временных затрат на осуществление трудовых операций конкретным сотрудником используются хронометраж, фотография рабочего дня, наблюдение, аналитическо-расчетный метод нормирования труда. Они довольно хорошо изучены как в отечественной, так и в зарубежной литературе. Однако определение затрат времени на оказание государственной услуги невозможно свести к исследованию затрат труда отдельного работника, поскольку в течение рабочего дня он может реализовывать не одну, а несколько государственных услуг, либо же в оказании одной государственной услуги принимают участие не один, а несколько работников. В этой связи становятся актуальными инструменты изучения затрат труда на оказание конкретной государственной услуги.

За последние несколько лет в данном направлении проделана серьезная работа. Если в 2012 г. для проведения исследования авторы данной статьи разрабатывали и применяли собственную методику проведения нормирования государственной услуги, то в настоящее время имеется ряд отраслевых методик нормирования государственных услуг [Чепляев, Бондаренко, Падалка 2012: 93]. Например, к ним относятся Методические рекомендации по разработке систем нормирования труда в государственных (муниципальных) учреждениях, и Методические рекомендации для федеральных органов исполнительной власти по разработке типовых отраслевых норм труда ${ }^{1}$. Однако в первую очередь они ориентированы на определение нормы численности сотрудников на основе типовых норм времени и типовых норм обслуживания, а не на описание технологии нормирования конкретной государственной услуги.

\footnotetext{
1 Приказ Министерства труда и социальной защиты РФ от 30.09.2013 № 504 «Об утверждении методических рекомендаций по разработке систем нормирования труда в государственных (муниципальных) учреждениях». - Справочная правовая система КонсультантПлюс. Доступ: www. consultant.ru/cons/cgi/online.cgi? req $=$ doc $\&$ base $=$ LAW $\& n=155090 \&$ fld $=134 \&$ dst $=1000000001,0 \& \mathrm{r}$ $\mathrm{nd}=0.8181836705511074 \# 05647661812240603$ (проверено 10.10.2018); Приказ Министерства труда и социальной защиты РФ от 31.05 .2013 № 235 «Об утверждении методических рекомендаций для федеральных органов исполнительной власти по разработке типовых отраслевых норм труда». Справочная правовая система КонсультантПлюс. Доступ: www.consultant.ru/cons/cgi/online.cgi?req= doc\&base $=$ LAW $n=149365 \&$ fld $=134 \& \mathrm{dst}=1000000001,0 \& \mathrm{rnd}=0.7527007515501924 \# 09381424518428267$ (проверено 10.10.2018).
} 
При применении указанных методических рекомендаций в различных областях деятельности возникают специфические проблемы. В октябре 2017 г., апреле 2018 г. авторы статьи определяли затраты труда на оказание государственных услуг сотрудниками ветеринарной лаборатории. Исследовалось 113 государственных услуг, оказываемых 9 структурными подразделениями.

В ходе анализа организационно-технических условий выполнения технологических (трудовых) процессов учитывались используемые технологии, методики, стандарты выполнения работ, параметры работы и обслуживания применяемого оборудования, условия труда на рабочих местах, формы организации труда, режимы труда и отдыха и другие параметры, в т.ч. регламентированные перерывы, характеристики выполняемых работ, рациональное разделение и кооперация труда.

Методика определения нормы численности работников на основе типовых норм времени, рекомендуемая для применения при нормировании государственной услуги приказом Министерства труда и социальной защиты РФ от 30 сентября 2013 г. № 504, характеризовалась наличием существенного методологического недостатка: при расчете трудозатрат на оказание услуги не учитывались совместное и одновременное выполнение трудовой операции несколькими участниками трудового процесса.

Проблемы возникли и при применении термина «типовая норма времени», поскольку в сфере деятельности ветеринарной лаборатории имеются только нормативы времени на проведение конкретного анализа, рассматриваемого в рамках проводимого исследования в качестве государственной услуги. Нормы времени на выполнение работ закреплены в ряде документов, таких как ГОСТ, МУ, ВМУ, инструкциях по применению различных тест-систем. Все они определяют нормативы времени на проведение анализа, не выделяя при этом трудозатраты конкретного работника. Подобные типовые нормы не дают возможности понять, какое число часов непосредственно затрачивается исполнителем на выполнение работы (затраты рабочего времени) и сколько часов задействовано только специальное оборудование, не требующее непосредственных затрат труда работников (аппаратное время).

Также типовая норма не разделяет объем выполняемых работ по должностям исполнителей. Например, при проведении лабораторной диагностики бешенства требуются затраты труда лаборанта, подготавливающего посуду, и ветеринарного врача, производящего анализ. При этом лаборант, занимающийся посудой, готовит ее не только для проведения диагностики бешенства, но и множества других анализов. И выделить трудозатраты лаборанта на оказание конкретной рассматриваемой государственной услуги довольно проблематично.

В этой связи для проведения исследования было произведено методологическое допущение: рассчитан общий фонд рабочего времени по структурному подразделению, затрачиваемый на выполнение услуги, без привязки к конкретной должности. Сумма фондов по всем услугам, оказываемым конкретным структурным подразделением, составила общий фонд рабочего времени, по отношению к которому и была применена формула расчета нормы численности. В итоге было получено обоснование численности работников подразделения.

Сбор данных в ходе нормирования труда производился с помощью следующих методов: 1) самофотография рабочего дня; 2) наблюдение (фотография рабочего времени); 3) экспертный опрос; 4) анализ документов; 5) анализ статистических данных; 6) хронометраж.

В качестве респондентов при проведении экспертных опросов выступали руководители отделов и работники, в совершенстве представляющие техно- 
логический процесс. Путем опроса был выявлен набор трудовых функций, выполняемых сотрудниками структурного подразделения ежедневно, еженедельно, ежемесячно и ежегодно и не имеющих типовых норм выполнения работ. Далее был рассчитан ежегодный объем трудозатрат на работы, носящие разовый характер, по которым не определены нормы времени.

Путем наблюдения и самофотографии рабочего дня уточнялись данные о числе трудовых операций, не имеющих типовых норм выполнения работ, выполняемых в течение дня.

В рамках определения порядка расчета нормативных затрат на оказание государственных услуг (выполнение работ) составлялись технико-нормировочные карты по видам работ, реализуемых в рамках отдельных направлений деятельности ветеринарной лаборатории. Методом изучения затрат труда выступал хронометраж.

По результатам проведенных замеров были выявлены трудовые элементы (операции) лабораторных исследований, определена их продолжительность.

За единицу работы принималась 1 проба; минимальной нагрузкой, как правило, выступала 1 проба; под средней нагрузкой понималось среднее число проб. Число единиц объема работ в одной операции рассматривалось как число проб за 1 испытание.

Фонд рабочего времени за 1 смену, а также сменное полезное время рассчитывались исходя из продолжительности рабочей недели, установленной для сотрудников конкретного отдела, и составлял 480 или 360 мин.

При проведении данной работы мы столкнулись с рядом проблем. Во-первых, выявить время, затрачиваемое исполнителем на 1 единицу работы (1 пробу), крайне затруднительно, поскольку одновременно сотрудник может проводить анализ, используя от 1 до 50 проб. При этом трудозатраты одинаковы как для 1 пробы, так и для 50. Во-вторых, крайне редко исполнитель занят постановкой только одного анализа. Одна и та же проба может одновременно исследоваться по разным направлениям (т.е. одновременно будет оказываться несколько государственных услуг). В-третьих, в связи с параллельным выполнением анализов проблематично определить минимальную, максимальную и среднюю загрузки исполнителя при оказании конкретной государственной услуги. В-четвертых, не каждая трудовая операция имеет четкие временные границы выполнения. Так, например, отбор проб может производиться с территории, расположенной на расстоянии как 3 км, так и 300 км от лаборатории, что требует разного времени доставки специалиста к месту работ. В-пятых, сложно вычлененить аппаратное время при проведении анализа. Затраты труда при реализации одной и той же государственной услуги могут значительно различаться в случае необходимости калибровки прибора. При проведении центрифугирования работник вроде бы сам и не выполняет какие-либо трудовые операции, но и продолжить постановку опыта не может. В-шестых, технологический процесс некоторых лабораторных испытаний предполагает их проведение в течение нескольких дней, при этом ежедневные трудозатраты работника никак не регламентируются. В-седьмых, перечень трудовых операций, выполняемых в рамках одного и того же анализа, может различаться. Например, для одних анализов калибровочный раствор может готовиться каждый раз, а для других он будет подготовлен один раз, а затем будет использоваться в нескольких опытах.

Довольно сложно вычленить в ходе рабочего дня и постоянные затраты рабочего времени каждого сотрудника.

В целом, в государственных учреждениях выстраиваются системы нормирования труда, нацеленные на повышение эффективности обслуживания потребителей государственных услуг путем обеспечения нормального уровня напря- 
женности (интенсивности) труда исполнителей при оказании государственных услуг.

Кроме того, нормирование труда в государственных учреждениях применяется для оптимизации численности персонала и расчета нормативных финансовых затрат на реализацию государственных услуг.

Порядок работ по нормированию закрепляется в специальном документе Положении о системе нормирования труда учреждения.

Применение нормирования для достижения указанных целей государственных учреждений сопряжено с рядом проблем:

1) с периодичностью проведения. В настоящее время мероприятия по нормированию труда реализуются бессистемно и носят разовый характер;

2) подготовкой субъектов нормирования. Разработка системы нормирования труда должна осуществляться специалистами, обладающими необходимыми знаниями и умениями в сфере организации и нормирования труда. Но на практике данный тезис применить крайне сложно. Это связано с отсутствием подготовки нормировщиков в образовательных организациях (ФГОС по данной специальности отменены) и постоянно проводимыми в государственных учреждениях мероприятиями по сокращению штатов;

3) настороженностью объектов оценки. Из-за эпизодического проведения замеров рабочего времени и, как правило, следующих после них организационно-штатных изменений работники воспринимают любые мероприятия, проводимые в рамках нормирования труда, настороженно;

4) низкой степенью доверия и заинтересованности в качественном проведении нормирования труда у всех участников данного процесса (администрации и работников);

5) слабой связью результатов оценки с последующими решениями;

6) отсутствием механизма, позволяющего увязывать меняющийся объем услуг с численностью работников.

С нашей точки зрения, для преодоления обозначенных проблем необходимо систематическое применение экспертного метода, опроса работников, самофотографий, проведение анализа полноты использования фонда рабочего времени. При этом результаты, полученные в ходе исследования затрат труда, не должны использоваться в качестве инструмента наказания.

Кроме того, на государственном уровне следует поднять вопрос о подготовке квалифицированных кадров в области нормирования труда, в т.ч. под потребности государственных учреждений [Шакирова 2014: 74].

Таким образом, должна быть выстроена система нормирования труда, которая позволит оптимизировать содержание, интенсивность труда работников государственных учреждений, а населению - получать качественные государственные услуги.

\section{Список литературы}

Чепляев В.Л., Бондаренко О.И., Падалка Е.А. 2012. Разработка методики нормирования государственных услуг. - Власть. № 12. С. 92-95.

Шакирова Н.Н. 2014. Современная практика нормирования труда. - Наука и общество. № 1(16). С. 71-75. 
BONDARENKO Oksana Ivanovna, Cand.Sci. (Soc.), Associate Professor; Lecturer at the College of Economics and Finance, Saratov Social and Economic Institute - branch of Plekhanov Russian University of Economics (24 Mezhdunarodnaya St, Saratov, Russia, 410052; oksana1136@yandex.ru)

OL'KHOVA Larisa Anatol'evna, Cand.Sci. (Econ.), Associate Professor of the Chair of Personnel Management and Psychology, Saratov Social and Economic Institute - branch of Plekhanov Russian University of Economics (89 Radisheva St, Saratov, Russia, 410003; 766627@mail.ru)

PADALKA Ekaterina Alekseevna, Senior Lecturer of the Chair of Personnel Management and Psychology, Saratov Social and Economic Institute - branch of Plekhanov Russian University of Economics (89 Radisheva St, Saratov, Russia, 410003; ekaterina.padalka@inbox.ru)

\section{METHODS OF RATIONING OF PUBLIC SERVICES: PROBLEMS OF APPLICATION}

Abstract. Interest in the rationing of labor by public institutions is associated with the solution of a number of problems. The first one is to increase the efficiency of providing public services to the population; the second one is the development of time standards for the realization of public services; the third one is the determination of the number of personnel of a public institution. The result of their solving is the development of technical and rationing cards for the employees of the laboratory of a public institution.

Keywords: labor rationing, labor rationing techniques, state services, standard time norms, technical normalization cards

УДК 316.3

БАДАРАЕВ Дамдин Доржиевич - кандидат социологических наук, старший научный сотрудник Института монголоведения, буддологии и тибетологии СО РАН (670047, Россия, Республика Бурятия, г. Улан-Удэ, ул. Сахьяновой, 6; damdin80@mail.ru)

ВАН Ирина Доржиевна - аспирант Института монголоведения, буддологии и тибетологии СО РАН (670047, Россия, Республика Бурятия, г. Улан-Удэ, ул. Сахьяновой, 6; irdon@yandex.ru)

\section{МОНГОЛЬСКИЙ КОРИДОР КАК РЕВИТАЛИЗАЦИЯ ВЕЛИКОГО ЧАЙНОГО ПУТИ: ВОЗМОЖНОСТИ РАЗВИТИЯ СОТРУДНИЧЕСТВА РОССИИ, МОНГОЛИИ И КИТАЯ}

Аннотация. Статья посвящена вопросам реализации программы экономического коридора «Россия Монголия - Китай». Представлен краткий исторический экскурс по маршруту Великого чайного пути, отмечены возможности продвижения центрального транспортного коридора Монголии как основы интересов каждой из трех сторон.

Ключевые слова: Великий чайный путь, монгольский экономический коридор, региональное сотрудничество

$\mathrm{P}$ оссию, Монголию и Китай на протяжении нескольких столетий связывают торгово-экономические, транспортно-логистические и социально-культурные связи. Великий чайный путь, являясь одним из самых известных кроссконтинентальных маршрутов, соединял Китай, Монголию, Россию и европейские страны в XVIII-XIX вв. В XX в. по территории Монголии от ее северной границы с Россией до южной границы с Китаем была проложена ширококо- 